\title{
Indústria cultural e mercantilização da cultura como projeto de semiformação na educação da infância moderna
}

\author{
Anilde Tombolato Tavares da Silva * \\ Sinésio Ferraz Bueno **
}

\section{Resumo}

O presente artigo se propõe delinear o caminho da reflexão adorniana sobre a Indústria Cultural, mercantilização da cultura e semiformação, por meio da revisão de literatura e apoio do referencial teórico metodológico da Teoria Crítica da Sociedade e, a partir daí, estabelecer uma reflexão acerca da importância do processo de formação cultural como projeto de emancipação do indivíduo. Nesse sentido, considera-se relevante pensar a maneira como a cultura torna-se veículo de semiformação ao invés de condutor para a emancipação na educação da infância moderna. Procura-se evidenciar que o indivíduo é estimulado a pensar-se como ser singular e livre, mas que constrói a partir da mercantilização dos bens culturais um espírito míope que o condiciona ao isolamento de si para si no mundo, mediante o princípio da conformidade.

Palavras chave: Indústria Cultural. Teoria Crítica. Semiformação. Educação.

* Doutora em Educação pela Universidade Estadual Paulista (UNESP), Campus Marília. Professora do Departamento de Educação da Universidade Estadual de Londrina(UEL).

** Doutor em História e Filosofia da Educação pela Universidade de São Paulo (USP). Professor do Departamento de Filosofia da Faculdade de Filosofia e Ciências e do Programa de Pós-Graduação em Educação da Faculdade de Filosofia e Ciências da Universidade Estadual Paulista "Júlio de Mesquita Filho" Campus Marília, São Paulo.

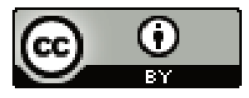




\section{Introdução}

As análises reflexivas sobre a Indústria Cultural, mercantilização da cultura e suas interfaces com a formação e a semiformação na sociedade moderna, ainda estão longe de serem dadas por encerradas. Tais relações e suas consequências, na consolidação, ou não, de uma cultura de mercado, precisam ser investigadas a fundo para que se possa compreender o sentido que a contemporaneidade vai dando ao processo formativo e, talvez, chegar a algumas propostas quanto às suas possibilidades de contribuir para uma educação emancipatória. A subsunção induzida dos indivíduos, órgãos e instituições no fortalecimento da sociedade de consumo e a mudança de valores e práticas socioculturais, em grande parte promovida pela mídia, no chamado "mundo globalizado", requer nossa atenção para que não nos deixemos iludir pelo novo “canto da sereia". Uma alusão à promessa de felicidade oferecida pela comercialização de bens materiais e culturais, num contexto em que a inserção social do indivíduo depende de sua identificação com os valores e produtos transformados em mercadoria, cuja necessidade de consumo é imposta pelos apelos da Indústria Cultural.

Estamos diante de um processo em que o desenvolvimento da produção e reprodução midiática no cenário contemporâneo imprime a sensação de aparente liberdade política, econômica e moral. A liberdade de fato autônoma, de usar o próprio entendimento, tem cada vez mais se reduzido à esfera da vida privada, uma vez que as escolhas precisam ser adequadas às necessidades e exigências do sistema de produção. Diante desta condição, o projeto de emancipação exige que a cultura e a arte possam desempenhar este papel de superar a persistente fetichização da técnica e a reificação das consciências, que materializam a ênfase sem medida nas relações de produção de mercadoria e consumo. A criança acaba sendo seduzida por esse processo de inculcação de ideologias e novas formas de pensar e ver o mundo, voltado para a adaptabilidade e conformidade, exigindo do trabalho do professor um olhar crítico à realidade em favor da superação daquilo que Adorno denunciou como semiformação. Uma crítica construída sobre a ideia de uma crise cultural e formativa que afeta o viver do homem em sociedade e sua relação com os bens culturais criados.

Este artigo se propõe a argumentar sobre a essência da Indústria Cultural, que não só permanece atual e interfere na concepção estética cultural e nas relações de consumo na sociedade contemporânea como também no processo de universalização da semiformação que permeia a educação escolar voltada para a infância. Para perseguir esta finalidade, busca-se, junto aos pensadores da Teoria Crítica, em especial Theodor Adorno, fazer uma análise crítica sobre o processo de "fabricação" da cultura e da arte, bem como de sua mercantilização, e, assim, pensar na ação da Indústria Cultural, que elimina a capacidade emancipatória da cultura e da arte. E, do mesmo modo, junto a Adorno, defender a formação cultural como 
forma de expressão e contestação, como um caminho ainda capaz de resistir ao progresso totalizante do esclarecimento e, a partir disso, construir outro percurso para compreender o processo formativo da infância na contemporaneidade, com vista à superação do que está posto pela indústria cultural.

\section{Indústria Cultural e a mercantilização da cultura}

A Indústria Cultural é uma realidade procedente da sociedade contemporânea, e seu conceito foi apresentado por Hokheimer e Adorno no livro Dialética do Esclarecimento: Fragmentos filosóficos, publicado em Amsterdã no ano de 1947, em substituição ao termo “cultura de massa", para ressaltar o “mecanismo" pelo qual a sociedade seria constituída sob a regência do capital, reforçando a realidade vigente. A intenção destes autores foi estabelecer um diálogo crítico entre cultura e barbárie e relacioná-la com a fragmentação e seriação da produção de mercadoria no capitalismo, dentro da mesma lógica do mundo do entretenimento, do lazer como processo extensivo da lógica do trabalho. Buscavam denunciar que, nas relações de troca de mercadorias, todas as relações sociais também são reduzidas ao valor de troca. O produto cultural perde seu brilho, sua unicidade e sua especificidade de valor de uso na mesma proporção com que dissolve sua verdadeira essência e se transforma em processo produtivo. Uma preocupação que tenta apreender a tendência à determinação total da vida em todas suas dimensões para formação social capitalista, revelando os sintomas do colapso da formação cultural de seu tempo (os anos 1960):

Quanto mais inexoravelmente o princípio do valor de troca subtrai valores de uso aos homens, tanto mais o próprio valor de troca se disfarça como objeto de fruição. Indagou-se pelo cimento que ainda mantém unida a sociedade das mercadorias [...]. A aparência do valor de troca nas mercadorias assumiu uma função específica de cimento. [...] A cultura de massa masoquista é a aparência necessária da todo poderosa produção ela mesma... Também na superestrutura a aparência não é apenas o encobrimento da essência, mas surge obrigatoriamente da essência. (ADORNO, 1999, p. 79).

Por meio do progresso tecnológico, a humanidade expandiu suas relações sociais e culturais, que se intensificaram a partir do que se chamou de Revolução Industrial. Foi deste período em diante que assistimos à reinvenção dos modos de subjeção inflexível ao valor de troca que modelaram o cotidiano cimentando à esfera da cultura ao processo produtivo. Há um confronto com uma realidade em que a sociedade passa a ser conduzida não por um projeto político e ideológico de emancipação do conhecimento, mas diante de uma sociedade totalmente conduzida pelo conhecimento técnico, que passa a ser a nova estrutura ideológica de mercantilização da cultura, alimentada pela Indústria Cultural. A técnica materializada por este processo cria condições para a implantação do comércio cultural. 
Se pensarmos no conceito de Indústria Cultural, podemos perceber a ambiguidade de seus termos: Indústria e Cultura, os quais, por um lado, se parecem expressar ideias excludentes e não se realizar completamente, por outro, assemelham-se ao processo industrial, quando destacam a estandardização de determinado objeto e quando dizem respeito à racionalização das técnicas de distribuição. A lógica do capital reinventa os modos de subjeção, influencia e modela a vida e a cultura e, por meio do processo industrial, obtém a marca do monopólio da cultura de massa através da serialização e da padronização.

A cultura passa a ser mais um negócio, e o conhecimento a corresponder a uma pedagogia cega e imunizada contra os processos autorreflexivos, ao invés de constituir-se como um processo dialético de apropriação subjetiva do processo de formação cultural capaz de preservar a tensão entre adaptação e crítica à realidade. A cultura converte-se em um processo semiformativo que prepara o indivíduo para o conformismo e a adaptação à realidade vigente. Estas particularidades engendradas na fetichização da técnica, na mercantilização da cultura e na reificação da consciência nada mais são do que, como disse Zuin (2001, p. 11), "mercadorias padronizadas que podem ser trocadas e que cobram seus dividendos na consolidação de sua individualidade danificada". No ensaio "A Indústria Cultural”, Adorno esclarece que:

Ao juntar elementos [da cultura] de há muito correntes, ela [Industria Cultural] atribuilhes uma nova qualidade. Em todos os seus planos são construídos de maneira mais ou menos planejada produtos que são talhados para o consumo pelas massas e que, em ampla medida, determinam por si mesmos este consumo. [...] Indústria Cultural é a integração deliberada, a partir do alto, de seus consumidores. (HORKHEIMER, ADORNO, 1985, p. 93, grifo nosso).

A relação entre indústria e cultura assume peso, espaço crescente e atuante em todos os instantes e lugares. A lógica das relações de produção de bens materiais e simbólicos, que resulta em uma cultura subsumida ao mercado de consumo e transfere para a posse dos objetos o prestígio social do sujeito, está dada pela repetição dos esquematismos industriais no instante de produção e lazer. Um argumento que ganha voz em uma utopia "abstrata que se ajustaria com demasiada facilidade as mais consumadas tendências da sociedade. Que todos os homens se assemelhem é o bem que lhe apraz" (ADORNO, 2008, p. 98). Assim, a Indústria Cultural vai conferindo a todos os seus produtos instrumentais e à própria cultura $u m$ ar de semelhança, de parentesco, fornecendo, por toda a parte, bens padronizados. Cada setor da produção é uniformizado, e todos o são em relação aos outros.

A Indústria Cultural reflete a falsa democratização da cultura realizada pela massificação e irracionalidade objetiva da sociedade capitalista como racionalidade da manipulação. Os saberes se fragmentam e se adaptam à permanente instrumentalização dos homens e das coisas e à sua subsunção inflexível ao valor de troca, administrando seu comportamento social como parte integrante das suas necessidades simbólicas no contexto mais amplo do desenvolvimento da sociedade industrial. Em uma via 
de mão dupla, utiliza-se da tecnologia e por ela é viabilizada. Ao mesmo tempo, é ferramenta e produto do sistema capitalista, sendo a principal via do sistema, caracterizada por sua dimensão acultural e técnica, pelo consumo de massas e pela mercadoria. Horkheimer e Adorno (1985, p. 36) afirmam que a cultura "simula uma sociedade digna do homem, o que não existe [...]", sentença reafirmada na introdução de Educação e Emancipação por Wolfgang Leo Maar, ao dizer que:

A Indústria Cultural determina toda a estrutura de sentido da vida cultural para a racionalidade estratégica da produção econômica, que se inocula nos bens culturais enquanto se convertem estruturalmente em mercadorias; a própria organização da cultura, portanto, é manipulatória dos sentidos dos objetos culturais, subordinando-os aos sentidos econômicos e políticos e, logo, a situação vigente. (ADORNO, 2003, p. 21).

A dimensão cultural, caracterizada até então como expressão estética humana que tinha uma concepção como via de expressão e contestação, desloca-se da dimensão estética/cultural, esvaziada de sentido, para reduzir-se a uma dimensão de diversão e lucro cuja finalidade é subsumir o sujeito à lógica do mercado de que se constitui a totalidade da organização social. A cultura e a arte transformam-se em mercadorias reproduzidas em série e designadas de acordo com os interesses do sistema econômico capitalista, passando a ser absorvidas pelos consumidores, que se tornam não o sujeito, mas o objeto dessa indústria. Nesse sentido, Horkheimer e Adorno, ao anunciar a Indústria Cultural enquanto prestadora de serviço ao cliente, afirmam:

Não se trata tanto para a indústria cultural de adaptar-se às reações dos clientes, mas sim de fingi-las. Ela as inculca neles ao se comportar como se ela própria fosse um cliente. Seria possível suspeitar que todo esse ajustamento, ao qual ela assevera obedecer também, é ideologia; as pessoas se esforçariam tanto mais para se igualar às outras e ao todo, quanto mais empenhadas estivessem - através da igualdade exagerada, esse juramento público de impotência social - em participar do poder e em minar a igualdade. [...] A indústria cultural modela-se pela regressão mimética, pela manipulação de impulsos de imitação recalcados. [...] Ela consegue fazê-lo tanto melhor quanto mais, em um sistema estabilizado, ela pode contar de fato com tal assentimento, precisando muito mais repeti-lo de maneira ritual do que, a rigor, produzi-lo. O que ela produz não é um estímulo, mas um modelo para maneiras de reagir a estímulos inexistentes. (HORKHEIMER; ADORNO, 1985, p. 176).

Horkheimer e Adorno (1985, p. 21) denunciam, assim, o processo do empobrecimento da autonomia estética do indivíduo em detrimento dos modelos impostos pela mercantilização da cultura e afirmam que, "no trajeto para a ciência moderna, os homens renunciaram ao sentido e substituíram o conceito pela fórmula, a causa pela regra e pela probabilidade". Assim, "toda a pretensão do conhecimento é abandonada". Quanto mais se afasta do conceito e da possibilidade de negação, mais o pensamento conforma-se com a mediocridade e com a repetição. Para os autores, "quanto mais a máquina do 
pensamento subjuga o que existe, tanto mais cegamente ela se contenta com essa reprodução" (HORKHEIMER; ADORNO, 1985, p. 38).

Como uma realidade fundante do capitalismo monopolista, a Indústria Cultural corresponde a um momento de consolidação dessa nova etapa da sociedade, na qual o próprio pensamento e todas suas consequências produzidas na esfera da cultura se tornam mercadoria. A cultura vista pelo ideal iluminista como manifestação do Espírito em contradição com a Matéria (dialética básica adorniana) torna-se matéria, sem mediações e sem sentido, trazendo suas consequências: o que deveria ser único e original (fruto da liberdade de criação artística) torna-se repetitivo, por submeter-se a uma fórmula em detrimento da forma, e o que era irredutível (essência do pensamento) torna-se derivado, porque submete-se a um gosto coletivizado pela moda do consumo. A cultura, a arte e a mercadoria estabelecem relações complexas entre si. Tem-se um exemplo disso quando o artista passa a "vender" sua obra no mercado, transformando-a em mera mercadoria, diluindo a autonomia estética e as emoções sedutoras inerentes a elas em meio ao processo de troca, sob a lógica de mercado.

A Indústria Cultural tornou-se mais um recurso da linguagem e do pensamento cotidianos resultante do mercado de ideias dominantes, transvestida de algo que se desenvolve espontaneamente a partir das massas e traduz-se como arte popular. A técnica moderna cria e revoluciona constantemente os novos instrumentos com o ciberespaço, aliando-se à globalização como modelo único. Neste sentido, a Indústria Cultural não só edifica a mercantilização da cultura como também é legitimada pela demanda desses produtos. A potencialização da experiência midiática e tecnológica parece ser a marca da modernidade, e os conteúdos gerados por ela servem como ponte entre o indivíduo e suas relações sociais mais amplas no universo do consumo, contribuindo para a articulação e formação das identidades.

Horkheimer e Adorno reiteram a força da "Indústria Cultural que não sublima, mas reprime e expõe" (1985, p. 131). E, ao analisar o impacto das inovações da produção industrial de massa na vida do homem, afirmam:

O fato de que suas inovações características não passem de aperfeiçoamento da produção em massa não é exterior ao sistema. É com razão que o interesse de inúmeros consumidores se prende à técnica, não aos conteúdos teimosamente repetidos, ocos e já em parte abandonados. O poderio social que os espectadores adoram é mais eficazmente afirmado na omnipresença do estereótipo imposta pela técnica do que nas ideologias rançosas pelas quais os conteúdos efêmeros devem responder. (HORKHEIMER; ADORNO, 1985, p. 127).

A formação da cultura massificada fortaleceu-se pela mediatização das tecnologias na percepção humana, percorrendo muitos caminhos, entre eles a tecnificação da sociedade, o processo de concentração urbana e a democratização da escola, propagando o conhecimento e permitindo mais acesso aos meios de 
comunicação de massa e tecnológicos. Neste processo, constata-se o ambiente necessário para formação de uma economia de mercado voltada para o consumo desta cultura que fatalmente produz um sintoma de uma vida sem qualidade no plano estético, criando uma tendência de acomodar-se diante de uma invasão da linguagem comunicativa, que se resume a uma comunicação entre seres a quem é vedada a comunicação. A Indústria Cultural contribui assim para o embrutecimento social, intensificando a consciência coisificada.

\section{Indústria Cultural como projeto de semiformação}

A possibilidade de emancipação da consciência é a construção ideal na orientação para intervenção social rumo à libertação do modo de reprodução vigente, porém a Indústria Cultural, como buscamos argumentar, parece indicar sua substituição pelo processo de semiformação, que determina o ordenamento de adequação e sujeição aos termos existentes da reprodução social. A cultura, como se apresenta hoje, já não pode ser mais apreendida como ideal emancipatório, mas sim como uma realidade conservadora que legitima a sociedade vigente e a reconstrói como cópia ordenada. Cabe então pensar, parafraseando Maar (2003), que a finalidade destinada aos sujeitos é reproduzir um mundo em que sua condição é a de sujeitados, em que sua sujeição é produzida em um tempo cuja cultura entrou em colapso, empobrecendo ainda mais as relações sociais dos homens. Isso se deve em grande parte ao "descaso" com a formação, que gerou o que Adorno chamou de semiformação.

As primeiras referencias que Adorno fez à semiformação aparecem na sua obra "Dialética do Esclarecimento", ao analisar as condições de reprodução da vida dos homens sob as relações de produção dominante na formação social da sociedade de massa, como forma social presente e cópia da subjetividade socialmente imposta por determinado modo de produção em todos os planos da vida, como objetivação coisificada. A semiformação seria a forma social da subjetividade determinada pela sociedade de massa, que não pode ser explicada a partir de si mesma porque resulta não só do processo de sujeição do indivíduo mas de como os homens se sujeitam a si próprios.

A falsa projeção é o usurpador do reino da liberdade e da cultura; a paranoia é o sintoma do indivíduo semicultivado. Para ele todas as palavras convertem-se num sistema alucinatório, na tentativa de tomar posse pelo espírito de tudo aquilo que sua experiência não alcança, de dar arbitrariamente um sentido ao mundo que torna o homem sem sentido, mas ao mesmo tempo se transformam também na tentativa de difamar o espírito e a experiência de que está excluído e de imputar-lhes a culpa que, na verdade, é da sociedade, que o exclui do espírito e da experiência. Uma semicultura que, por oposição à simples incultura, hipostasia o saber limitado como verdade, não pode mais suportar a ruptura entre o interior e o exterior, o destino individual e a lei social, a manifestação e a essência [...]. A semicultura, em seu modo, recorre esteriotipadamente à fórmula que lhe convém melhor em cada caso, ora para justificar 
a desgraça acontecida, ora para profetizar a catástrofe disfarçada, às vezes de regeneração. (ADORNO, 1985, p. 182).

Percebe-se nesta passagem um conflito entre o interior e exterior do indivíduo, presente como a própria reificação da objetivação humana, consolidando a adaptação e abalando cada vez mais os elementos essenciais da formação e da emancipação: a autonomia e a liberdade. O que cabe aos sujeitos semiformados é promover a reprodução da realidade mediada pelo consumo ilimitado de produtos culturais; assim, cumpre a cada um deles reproduzir a si mesmo e ao sistema, e desse modo a "cultura converteu-se totalmente numa mercadoria, difundida como uma informação, sem penetrar nos indivíduos dela informados" (HORKHEIMER; ADORNO, 1985, p. 184). A semiformação converteu-se em espírito objetivo que transforma a todos em sujeitos do mundo que apenas reproduzem. O saber e o pensamento são neutralizados e mobilizados para a qualificação exigida pelo mercado de trabalho específico, aumentando o valor mercantil do próprio sujeito.

No processo de apropriação do espírito na formação social, o caminho se faz pelo processo de produção e reprodução da vida consolidados pelos sujeitos nele (semi)formados, em uma integração voluntária em que formam sua consciência e confirmam o mundo da ordem estabelecida, dando uma falsa sensação de autonomia do pensamento. A semiformação estaria na ordem desta forma social da subjetividade determinada nos termos do capital, e a cultura estaria em colapso, mediatizada entre a sociedade e a semiformação.

Em seu texto "Teoria da Semicultura" (1996), Adorno argumenta que a cultura tem duplo caráter: é, ao mesmo tempo, autonomia, liberdade do sujeito e adaptação, conformação à vida real. Se, de um lado, dentro da tradição da filosofia alemã, a bildung (formação) carrega consigo a tarefa de formar os homens amparada na ideia de autonomia e emancipação do sujeito; de outro, o fracasso do ideal de uma sociedade racional, igualitária e justa, proposta pela cultura burguesa, permitiu que a formação se satisfizesse em si mesma, em uma ilusão da realidade, convertendo-se em valor em si, dissociando-se da produção cultural da sociedade.

A formação cultural agora converteu-se em semiformação socializada na onipresença do espírito alienado que, segundo sua gênese e seu sentido, não antecede a formação cultural, mas a sucede. Desse modo, tudo fica aprisionado nas malhas da socialização. Nada fica intocado na natureza, mas sua rusticidade - a velha ficção - preserva a vida e reproduz-se de maneira ampliada. (ADORNO, 1996, p. 389).

Um processo que faz parte do âmbito da reprodução da vida e se instala na sociedade massificada em direção à barbárie, pois cada vez mais a cultura é colocada em oposição à práxis e entendida somente como cultura do espírito. A semiformação, fruto da crise dos processos formativos e emancipatórios da 
cultura, universalizou-se graças ao aparato técnico da produção e reprodução da cultura de massa. É o espírito conquistado pelo caráter do fetiche da mercadoria que revela a realidade social, na qual as diversas formas de expressão artística, que gozavam de uma autonomia estética, como obras de arte e música, foram convertidas em "pseudocultura" pelos monopólios comerciais em nome da democratização cultural, tornando-se forma dominante da consciência contemporânea.

Adorno coloca em foco a falta de autonomia ao referir-se à "estética do efeito", pela via da análise da cultura musical, que leva a um processo de redução da "apreciação musical ao prazer ou à diversão, derivados da audição, subordinando a música séria às exigências da indústria do entretenimento comercial, condicionando o ouvinte a um tipo de audição regredida e convertendo a cultura musical numa cultura de aparência" (CARONE, 2003, p. 479). Uma denúncia do empobrecimento da experiência musical e de como a música clássica, em nome de uma pseudodemocratização da cultura, foi convertida em mercadoria, durante o processo de racionalização da sociedade, pelos monopólios comerciais da música, falhando em levar aos ouvintes uma relação viva e real com a música.

Diante de uma sociedade essencialmente capitalista, na qual o mercado contribui para a sujeição do sujeito à reprodução da realidade e provoca efeitos no comportamento daquele que vai consumir a mercadoria cultural, a estética do efeito mostra suas garras com mais afinco no processo de mercantilização dos produtos culturais, por meio do qual a sua apreciação está fadada a se converter em prazer e diversão. "Não significa a adoração aos músicos, mas sim respeito pela obra, manifestado pela preocupação do ouvinte com o sentido musical per se" (CARONE, 2003, p. 488). Estende-se também à cultura materializada nas diversas formas de expressão artística, que se torna, assim, mercadoria fetichizada para o mercado de produção. A autonomia estética materializada em arte e cultura se transfere para a ideologia de mercado.

A produção da cultura e da arte superior no âmbito da Indústria Cultural nada mais é que mercadoria cultural, que deve ser absorvida pelos consumidores, que se tornam não o sujeito, mas o objeto dessa indústria. Não se trata somente do empobrecimento da autonomia estética e dos interesses materiais, mas também da necessidade de incorporá-los refletidamente nas relações humanas, para assim avançar na liberdade criativa. Identificar a cultura somente pela mentira torna-se perigoso à medida que a cultura tornase realmente uma produção em série mentirosa, que atinge profundamente uma identificação e compromete qualquer pensamento resistente sobre ela, cujo "olhar sobre a vida transferiu-se para a ideologia, a qual esconde que não há mais vida” (ADORNO, 2008, p. 9).

A produção cultural artística, já infectada pela padronização e seriação dos processos de industrialização, transforma a relação de trocas simbólicas, a circulação e o consumo destes produtos e 
perde sua essência de autonomia e liberdade de expressão. "A liberdade absoluta da arte, que é sempre a liberdade num domínio particular, entra em contradição com o estado perene de não liberdade no todo" (ADORNO, 1988, p. 11). Ou seja, ao objetivar fins desde a produção até a circulação e consumo, os bens culturais produzidos pela Indústria Cultural deixam de ser autônomos, contrariando um princípio inerente ao processo formativo e emancipatório que é da própria liberdade.

$\mathrm{Na}$ indústria do entretenimento, do lazer administrado, da cultura vinculada ao consumo de massa, a arte se reduz à mercadoria, perde sua autonomia e seu potencial crítico ao fetiche do consumo. Para Adorno (1988, p. 24), “a experiência estética só é autônoma quando se desembaraça do gosto da fruição. A via que aí conduz passa pelo desinteresse". A exposição e vivência efêmera da arte na Indústria Cultural, sua duração estética como valor de troca, tornaram-na obsoleta, despotencializando sua ação de negatividade. A arte autêntica constitui-se em uma força negativa, de estranhamento do sujeito em relação à realidade dada. Neste vínculo entre arte e sociedade como espírito que move a subjetividade do artista, Adorno propõe:

Que as obras de arte, como mônadas sem janelas, "representem" o que elas próprias não são, só se pode compreender pelo fato de que a sua dinâmica própria, a sua historicidade imanente enquanto dialética da natureza e do domínio da natureza não é da mesma essência que a dialética exterior, mas se lhe assemelha em si, sem imitar. (ADORNO 1988, p. 16).

Na Indústria Cultural, a arte se afasta de algumas características, como a unicidade do produto, sua identificação com o produtor, a sua autenticidade e sua aura, que demarcam a tensão entre subjetividade e movimento histórico. As produções simbólicas da cultura reforçam a lógica da produção capitalista como decorrência da seriação e divisão do trabalho na indústria da fragmentação do processo de produção e comercialização em massa. A lógica da reprodução técnica dos bens simbólicos, a homogeneização dos padrões culturais e produção seriada mostram que a existência da arte industrial relaciona-se com formas de representações reificadas, repressivas, que acomodam a tensão entre sujeito e realidade, própria da arte. Assim, a obra de arte se sujeita à técnica que permeia as práticas de relações capitalistas.

Consequência disto é a percepção de um definhamento do elemento crítico do homem atuando como mero instrumento a serviço da ordem existente. O pensamento se vê privado "não só do uso afirmativo da linguagem conceitual científica e cotidiana, mas igualmente da linguagem da oposição" (HORKHEIMER; ADORNO, 1985, p. 12). A sociedade acaba por absorver submissamente as verdades da ciência positiva, empurrando os indivíduos para uma semiformação. Neste caminho, os autores afirmam:

É ainda muito otimista pensar que o indivíduo esteja sendo liquidado com o osso e tudo. Pois mesmo na sua negação pura e simples, na supressão da mônada através da solidariedade, estaria plantada ao mesmo tempo a salvação do ser singular, que apenas na sua relação com o universal tornar-se-ia um particular. A situação atual está muito 
distante disso. [...] Em meio às unidades humanas padronizadas e administradas, o indivíduo vai perdurando. [...] Seu temperamento vivo e sem inibição, suas ideias inesperadas, sua originalidade, ainda que isso não passe de uma particular feiura, até mesmo sua algaravia, transforma o que é humano em traje de clown. Submetidos ao mecanismo universal da concorrência e não podendo se adequar ao mercado nem se impor nele de outra forma que não seja através da fixação de sua alteridade, mergulham de maneira apaixonada no seu próprio privilégio, exagerando a tal ponto que chegam a erradicar por completo aquilo que são tomados. Eles se vendem como fornecedores de calor humano em meio a frieza comercial [...]. (HORKHEIMER; ADORNO, 1985, p. 118).

Isso nos leva a pensar sobre os conteúdos veiculados na formação cultural dos indivíduos, que, por serem veiculados aos aligeiramentos e imediatismos informativos, sustentam um empobrecimento civilizatório que resulta em uma formação social regressiva que os enquadra nos modelos do mercado e da produção. Esse empobrecimento formativo nada mais é do que o conjunto de características próprias à vida social coletiva, acarretando ações bárbaras e violentas, próximas do meramente instintivo, atitudes comportamentais reducionistas e imitativas, como o "ignorante feliz, o egoísta simulado, o autorreferente venerado, a idolatria das celebridades narcísicas, a estereotipia corporal, o intelectualismo postiço, o mercantilismo estético, mistificação religiosa do desamparo político etc." (DUARTE, 2003, p. 23). A Indústria Cultural se aproveita deste pano de fundo do aligeiramento formativo no âmbito da cultura e da semiformação para subordinar a cultura ao fetiche da mercadoria.

Uma ideia que exige um olhar para além dos muros da pedagogia e do trabalho docente, pois o foco do problema formativo é muito maior do que o imposto sobre o refletir pedagógico, mas nem por isso o exclui, ao contrário, são complementares e ambos necessários para compreensão total, e não apenas fragmentária, da relação do indivíduo e de sua realidade cultural. Uma proposta que Adorno reflete no texto A filosofia e os Professores (2003), tecendo sua crítica à educação administrada e à experiência formativa implícita nos próprios conceitos, ressaltando o sentido da reflexão filosófica necessária ao trabalho docente e à educação, que devem distanciar-se de um fazer instrumentalizado e técnico e impor-se como objetivo, sentido e direção para uma educação emancipatória.

Muitas vezes, a emancipação é tomada na sua acepção instrumental e ideológica, servindo como slogan da função educativa na escola, aproximando-se mais da apreensão do conhecimento como mercadoria que do sentido de emancipação defendido por Adorno. Essa apreensão indevida da emancipação em relação à educação e ao processo formativo traz consigo a problemática do esvaziamento da formação do sujeito, na qual o obstáculo encontra-se nessa ausência da formação cultural, que, para Adorno (2003, p. 63), é uma “colcha de retalhos formada de declamação ideológica 
e de fatos que foram apropriados, isto é, na maior parte das vezes decorados, revela que foi rompido o nexo entre objeto e reflexão". Expõe, assim, a necessidade de uma formação filosófica mediada pela liberdade, autonomia e, essencialmente, pela formação cultural, entendida como experiência formativa.

Adorno (2003, p. 9), então, vai afirmar a necessidade de que

[...] os futuros professores tenham uma luz quanto ao que eles próprios fazem, em vez de se manterem desprovidos de conceitos em relação à sua atividade. As limitações objetivas que, bem sei, se abatem sobre muitos, não são invariáveis. A autorreflexão e o esforço crítico são dotados por isso de uma possibilidade real, a qual seria precisamente o contrário daquela dedicação férrea pela qual a maioria se decidiu. Esta contraria a formação cultural e a filosofia, na medida em que de antemão é definida pela apropriação de algo previamente existente e válido, em que faltam o sujeito, o formando ele próprio, seu juízo, sua experiência, o substrato da liberdade.

A formação é, assim, experiência formativa em que o sujeito apropria-se da cultura como produção humana no seu sentido amplo, emancipador. Uma apropriação dos conceitos e particularidades relativas ao saber filosófico, não como reprodução ou cópia da realidade mas como interrogação, questionamento de uma realidade que não se deixa apreender de maneira fixa, imediata, como busca da compreensão das mediações que só se evidenciam no exercício do pensamento feito pelo sujeito que não se prende aos moldes da filosofia estritamente profissional, pela via daquilo que pode erigir como possibilidade emancipatória de outra realidade. A formação deve ser compreendida como cultura pela sua apropriação subjetiva; de outra forma, converte-se no seu contrário, ou seja, o sujeito nega-se a si mesmo onde mais pensa existir e, por sua vez, a cultura retira de si o caráter emancipador que o constitui, contribuindo para a continuidade e repetição daquilo que existe. A formação cultural só pode existir e ser adquirida mediante esforço espontâneo e interesse, portanto não pode ser garantida simplesmente por meio da frequência de cursos. Adorno (2003, p. 64) assevera que “ela nem mesmo corresponde ao esforço, mas sim à disposição aberta, à capacidade de se abrir a elementos do espírito, apropriando-os de modo produtivo na consciência, em vez de se ocupar com os mesmos unicamente para aprender, conforme prescreve um clichê insuportável”.

Adorno (2003, p. 141) delega ao processo formativo a tarefa da "produção de uma consciência verdadeira". Neste sentido, a consciência passa a ser a referência para a compreensão da dimensão para além dos muros da pedagogia e, portanto, a proposta teórica de Adorno sobre a formação cultural parte da necessidade de formação para a consciência autodeterminada, tomando o devido cuidado para que esta formação não se converta ela mesma em semiformação, quando entendida apenas como 
conformação à vida real, como momento de adaptação e reprodução, reforçando apenas o desideratum da acomodação. Diz ele:

Quando o campo de forças a que chamamos formação se congela em categorias fixas sejam elas do espírito ou da natureza, de transcendência ou de acomodação -, cada uma delas, isolada, se coloca em contradição com seu sentido, fortalece a ideologia e promove uma formatação regressiva. (ADORNO, 1996, p. 2).

A educação escolar está cada vez mais constituída por uma experiência social e cultural homogeneizada e mercantilizada e, portanto, não é idealizada pela emancipação nem tampouco dialeticamente baseada na crítica da semiformação real, orientando-se por possibilidades presentes, embora não concretizadas na experiência das contradições da formação social efetiva.

Adorno propõe que, se o professor não estiver disposto e aberto para este esforço espontâneo, então que não se dedique à tarefa de ensinar, pois a formação instrumentalizada e limitada à profissionalização tende a aprisionar o conhecimento e a impedir o exercício da autonomia. No lugar da consciência reflexiva, a formação docente retira de si o elemento crítico essencial do professor que se quer mais do que um simples especialista e instaura-se o aprisionamento aos termos filosóficos, aos chavões, cristalizando a consciência coisificada, financiada pela Indústria Cultural, distanciando-se da reflexão sobre o objetivo, sobre o trabalho e sobre a realidade. É sobre esta forma de pensar que Adorno (2003, p. 70) afirma: "as pessoas acreditam estar salvas quando se orientam conforme regras científicas", e nesse sentido, ao invés do trabalho intelectual, "a observação científica converte-se num substituto da reflexão intelectual do fatual". É potencial da reflexão filosófica inerente ao trabalho docente levantar-se contra as fragmentações e jargões que retiram de si qualquer caráter filosófico, especificamente na atividade pedagógica da formação do espírito crítico desde a mais tenra infância.

\section{Algumas considerações....}

Pensar na possível relação entre a Indústria Cultural e a mercantilização da cultura na educação da infância mediante uma realidade social que nos expropria cada vez mais da possibilidade de ter experiência, que nos silencia e nos leva ao empobrecimento da autonomia criativa, da prática pedagógica do professor e do processo formativo é pensar em uma reação que só pode vir de uma educação para resistência. Só é possível compreender a força da Indústria Cultural se compreendermos o sentido da autonomia estética dentro das reflexões adornianas. Sem sensibilidade criativa e reflexiva, 
não se pode compreender o processo de dessensibilização e semiformação que está em marcha na nossa sociedade.

A educação escolar, com todos os seus artefatos pedagógicos utilizados pelo professor, junta-se aos da Indústria Cultural, provocando a composição de uma espécie de comutação da consciência humana, que é, necessariamente, a repetição mecânica da consciência forjada no contexto da racionalidade instrumental, configurada pelo pragmatismo cultural que tomou conta do ambiente social massificado contemporâneo. Sem dúvida, um cenário no qual é possível vislumbrar as crianças como verdadeiros consumidores compondo a malha social alienante, dividido e subdividido em níveis de consumo. Cada grupo está mapeado e deve consumir a gama de opções à sua disposição. O que nos coloca diante de uma crise da formação que se apoia na expressão mais desenvolvida da crise social da sociedade moderna. A educação não mais diz respeito só à formação da consciência de si, ao aperfeiçoamento moral ou à conscientização, mas sim à possibilidade de escapar de armadilhas que a Indústria Cultural nos impõe pela via do mercado, pois "cria um sujeito social identificado a uma subjetividade socializada de modo heterônomo, que rompe a continuidade do processo formativo de um modo fortuito" (ADORNO, 2003, p. 25).

No espaço escolar, essa força é cada vez mais atuante e age sobre o profissional de educação (de)formado pela Indústria Cultural, enfraquecido e desorganizado culturalmente, com parcos conhecimentos, onde a imagem que predomina é a da semiformação como um senso de verdade irrefutável. Por outro lado, os "pacotes" de programas curriculares definem os conteúdos, as estratégias e os recursos a serem usados, deixando pouca ou nenhuma liberdade de trabalho para o profissional da educação, tolhendo seu processo criativo. A semiformação é o espírito tomado pelo caráter fetichista da mercadoria e, como vivemos numa sociedade de consumo, o conhecimento e a cultura tornaram-se mercadorias sujeitas às normas paradoxais em relação à sua natureza.

O processo de desintegração do ser humano provocado pela contemporaneidade e pela Indústria Cultural reprime e manipula nossos sentidos, interfere na percepção que temos do mundo. É neste sentido que a visualidade desempenha importante papel, vislumbrando possibilidades de resistência à padronização imposta pela sociedade contemporânea. Para a construção desta percepção é necessária uma disposição do indivíduo, uma sensibilidade para a Arte, e com a mediação do professor, a criança pode "ver, observar, sentir, fazer e expressar", percebendo o mundo a sua volta com outra significação.

A apropriação de uma teoria e das práticas cotidianas que permitem uma leitura para além da utilidade e padronização da criatividade humana devolve, efetivamente, aos espaços escolares e, 
especificamente, ao educador o exercício de sua atividade intelectual, ao viabilizar uma nova atitude, pautada nos pressupostos de valorização da criança, oportunizando-lhe o desenvolvimento de suas possibilidades humanas e sociais, principalmente a formação da individualidade infantil e da expressão do seu pensamento criativo. Talvez este seja um dos caminhos para uma sociedade emancipada, entendida não como um estado unitário, mas sim como "a realização do universal na reconciliação das diferenças" (ADORNO, 2008, p. 99).

Verificamos, nesse novo tempo social, a expropriação da possibilidade de reflexão empobrecendo os processos da autonomia estética. Ficamos com a sensação de que à educação resta a apropriação do conhecimento produzido pelas ciências modernas, e ao ensino a função de apresentador desses saberes, deixando, portanto, de ser necessariamente um fator de emancipação ou transformação para se tornar um sentimento de impotência, de ilusão, que faz aumentar nossos medos e angústias através da padronização estereotipada da cultura. Ousamos afirmar que a escola contemporânea acaba por reproduzir a lógica da Indústria Cultural, tornando-se um lugar de propagação da sociedade do espetáculo, e não mais o espaço para criação reflexiva e conhecimento elaborado.

O profissional que atua com a criança tem o desafio de articular os conhecimentos e leituras de mundo nas práticas pedagógicas e na percepção estética, que pode ser construída na escola pela crítica à Indústria Cultural e à anestesia dos sentidos provocada por ela. Se as subjetividades são construídas com influência da Indústria Cultural, então isso significa que também podem ser "desconstruídas" e ressignificadas a partir da resistência e da intervenção crítica dos educadores visando a uma educação emancipatória. Porém, vale ressaltar que a educação, para ser efetiva, deve ser crítica da semiformação real, deve aplicar toda sua energia para se tornar "uma educação para a contradição e para a resistência" ao existente, para se contradizer e resistir como modo de ir além do plano da reconstrução cultural e da vigência da semiformação, referindo-se ao plano da vida real efetiva. A resistência se constrói pelo poder educativo do pensamento crítico e da autorreflexão, para se manter viva a chama da crença que o indivíduo, mesmo que subsumido pela Indústria Cultural, ainda pode se reencontrar na sua especificidade. Para Adorno:

A ideia de que o mundo quer ser enganado tornou-se mais verdadeira do que, sem dúvida, jamais pretendeu ser. Não somente os homens caem no logro, como se diz, desde que isso lhes dê uma satisfação por mais fugaz que seja, como também desejam essa impostura que eles próprios entreveem; esforçam-se por fecharem os olhos e aprovam, numa espécie de autodesprezo, aquilo que lhes ocorre e do qual sabem porque é fabricado. Sem o confessar, pressentem que suas vidas se lhes tornam intoleráveis tão logo não mais se agarrem a satisfações que, na realidade, não são. (ADORNO, 1986, p. 96). 
O próprio Adorno nos dá o caminho para finalizar este texto, com a possibilidade de pensarmos que o mesmo esforço e determinação empreendido pelos homens que caem no logro para se deixarem enganar e seduzir pelos "encantos da Sereia" da Indústria Cultural, utiliza-se da escola, na contramão destas imposturas, abrindo as portas para o exercício criativo da criança, que pode gerar, quem sabe, espaços de vida e formação de indivíduos críticos e transformadores: “[...] mostrando-se aos alunos as falsidades" presentes na vida da sociedade culturalmente construída e "despertando a consciência quanto a que os homens são enganados de modo permanente" (ADORNO, 2003, p. 181-183). Um sinal de reconhecimento daquilo que não devia ser assim, mas pode ser diferente. 


\section{REFERÊNCIAS}

ADORNO, Theodor W. Indústria Cultural. Tradução: Amélia Cohn. In: COHN, Gabriel. Theodor W. Adorno. Sociologia. São Paulo: Ática, 1986.

. Teoria Estética. Tradução: Artur Morão. Lisboa: Martins Fontes, 1988.

Teoria da semicultura. Educação e Sociedade, Campinas, n. 56, p. 388-411, dez. 1996. Disponível em: <http://adorno.planetaclix.pt/tadorno.htm>. Acesso em: 9 dez. 2015.

. Textos Escolhidos. São Paulo: Nova Cultural, 1999.

A Arte é Alegre? In: RAMOS-DE-OLIVEIRA, Newton; ZUIN, Antônio Alvaro Soares; PUCCI, Bruno (org.) Teoria Crítica, Estética e Educação. Campinas, SP: Autores Associados; Piracicaba, SP: UNIMEP, 2001. p.11-19.

. Educação e Emancipação. Tradução: Wolfgand Leo Maar, São Paulo: Paz \& Terra, 2003.

Mínima Moralia: Reflexões a partir da vida lesada. Tradução Gabriel Cohn. Rio de Janeiro: Beco do Azougue, 2008.

CARONE, Iray. Adorno e a Educação Musical pelo rádio, Educação e Sociedade, v. 24, n. 83, ago. 2003.

COSTA, Belarmino Cesar Guimarães da. Estética da Violência. Campinas, SP: Autores Associados; Piracicaba, SP: Editora UNIMEP, 2002.

- Indústria Cultural, mediação tecnológica e o potencial crítico da arte, In: RAMOS-DEOLIVEIRA, Newton; ZUIN, Antônio Alvaro Soares; PUCCI, Bruno (Orgs.) Teoria Crítica, Estética e Educação, Campinas, SP: Autores Associados; Piracicaba, SP: UNIMEP, 2001. p. 147-160.

DUARTE, Rodrigo. Teoria Crítica da Indústria Cultural. Belo Horizonte: UFMG, 2003.

HORKHEIMER, Max; ADORNO. Dialética do Esclarecimento. Fragmentos filosóficos. 2. ed. Tradução: Guido Antonio de Almeida. Rio de Janeiro: Jorge Zahar, 1985.

MAAR, W. Leo. Adorno, Semiformação e Educação, Educação e Sociedade, Campinas, v. 24, n. 83, p. 459-476, ago./2003.

ZUIN, Antonio A. S. Sobre a atualidade do conceito de Indústria Cultural, Caderno CEDES, Campinas, ano XXI, v. 21, n. 54, p. 9-18, ago. 2001.

Indústria Cultural e Semiformação: a atualidade da educação após Auchwitz. Revista

Educação e Filosofia, Uberlândia, v. 25, n. 50, p. 607-634, jul./dez. 2011. 
Cultural Industry and Commercialization of the

Culture as a Semi-formation Project in Modern

Children's Education

\begin{abstract}
This article aims to highlight the ways the Adornian reflection about Cultural Industry, commercialization of the culture and semiformation by literature revision and help from the methodological theoretical background from the critical theory of the society, and, then establish a reflection about the importance in the cultural formation as a project of individual emancipation. In this way, it's considered important to think how the culture turns into a vehicle of semi-formation instead of a conductor to the emancipation in the modern children's education. Trying to make the individual see herself/himself as singular and free, but, being able to build from the commercialization of cultural goods, a blind spirit that conditions to isolation of himself/herself in the world, upon the principal of conformism.
\end{abstract}

Key words: Cultural industry. Critical theory. Semi-formation. Education.

Anilde Tombolato Tavares da Silva

E-mail: anildetombolato@gmail.com

Sinésio Ferraz Bueno

E-mail: sinesioferraz@yahoo.com.br
Industria cultural y la mercantilización de la cultura y los proyectos de la semi formación en la educación de la infancia moderna

\section{Resumen}

En este artículo se pretende esbozar el camino de la reflexión de Adorno en la industria de la cultura, la mercantilización de la cultura y semi formación através de revisión de la literatura y semi-formación por revisión de la literatura y la ayuda de la base teórica metodológica de la teoría crítica de la sociedad y de allí establecer una reflexión sobre la importancia de proceso de formación cultural como el proyecto de emancipación individual. De esta manera, se considera importante pensar cómo la cultura se convierte en un vehículo de semiformación en lugar de un conductor a la emancipación en la educación de los niños modernos. Tratando de hacer que el individuo ve a sí misma / mismo como singular y libre, pero, al ser capaz de construir a partir de la comercialización de bienes culturales, un espíritu que ciega a las condiciones de aislamiento de sí mismo / a sí misma en el mundo, sobre el principio de conformismo.

Palabras clave: Industria cultural. La teoría crítica. Semi-formación. Educación.

Enviado em: 17/05/2016

Aprovado em: 05/05/2017 